ASAS/EULAR management recommendations for axSpA, the C-reactive protein (CRP)-based ASDAS is the preferred instrument for the assessment of disease activity in the process of making decision on modification of axSpA treatment in clinical routine. Currently, measurement of CRP by routine lab methods takes hours to days what seriously challenges the feasibility of T2T approaches in clinicalroutine and clinical studies.

Objectives: To compare the performance of the ASDAS based on a quickCRP assay (ASDAS-quick-CRP) with the ASDAS-routine-CRP and with the erythrocyte sedimentation rate (ESR)-based ASDAS in the assessment of disease activity in patients with axSpA.

Methods: This cross-sectional study was performed in patients referred with a suspicion of axSpA as part of the Identification of the Optimal Referral Strategy for Early Diagnosis of Axial Spondyloarthritis (OptiRef) study. Briefly, referred patients underwent a structured assessment of SpA features by a rheumatologist. CRP was measured in the central lab (routine turbidimetric assay, lowest detection level: $0.3 \mathrm{mg} / \mathrm{L}$ ) and locally by ESR and a quantitative quick-CRP test (QuickRead go, Orion Diagnostica Oy, lowest detection level: $5 \mathrm{mg} / \mathrm{L}$, test duration approx. 2 min.). If the quick-CRP was below the limit of detection, the value of $2 \mathrm{mg} / \mathrm{L}$ was used. In patients with the final diagnosis of axSpA, ASDAS-routineCRP, ASDAS-quick-CRP and ASDAS-ESR were calculated.

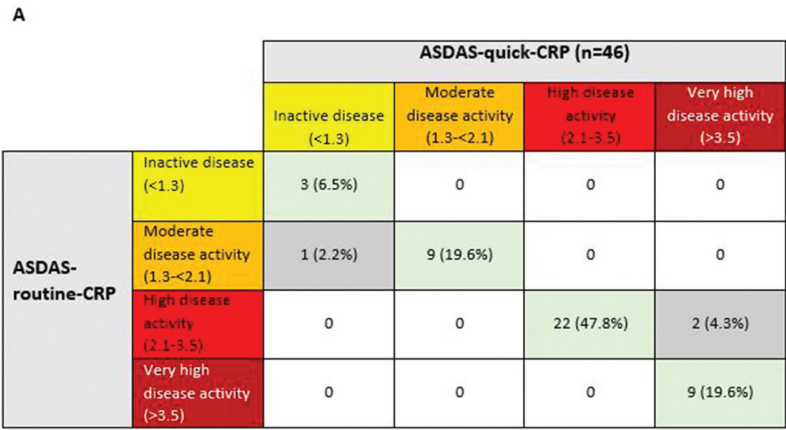

B

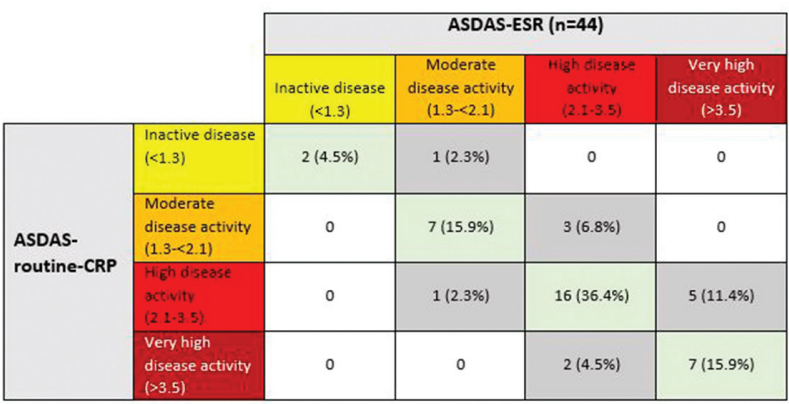

Abstract FRI0194 - Figure 1. Comparison of the disease activity state ascertainment by ASDAS-routine-CRP vs. ASDAS-quick-CRP (A) and ASDAS-routine-CRP vs. ASDAS-ESR (B).

Results: A total of 132 patients referred with suspicion of axSpA had available routine and quick CRP levels; 46 patients of them were diagnosed with axSpA. Mean $\pm S D$ routine/quick CRP serum levels were $3.20 \pm 6.86 \mathrm{mg} / \mathrm{L}$ and 4.52 $\pm 6.78 \mathrm{mg} / \mathrm{L}$, respectively, in the entire group, and $7.09 \pm 10.18 \mathrm{mg} / \mathrm{L}$ and 8.22 $\pm 10.11 \mathrm{mg} / \mathrm{L}$, respectively, in patients with axSpA. There was no significant difference $(p=0.11)$ in the mean values of ASDAS-CRP $(2.76 \pm 0.97)$ and ASDAS-quick-

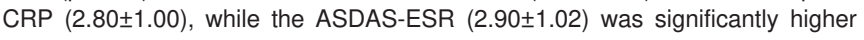
than ASDAS-routine-CRP ( $p=0.034)$. In 43 of the 46 cases of axSpA (94\%) the status scores for disease activity showed no difference between ASDAS-routineCRP and ASDAS-quick-CRP - figure 1. Two patients were assigned to a higher and one to a lower disease activity category (DAC) according to ASDAS-quickCRP as compared to ASDAS-routine-CRP. For ASDAS-ESR compared to ASDAS-routine-CRP, only $32 / 44$ patients (73\%) were assigned to the same DAC. Conclusions: ASDAS-quick-CRP performed similarly well to ASDAS-routineCRP with an agreement on the status score for disease activity of $94 \%$, that was clearly better than the agreement of $73 \%$ between ASDAS-ESR and ASDAS-routine-CRP. With a duration of approximately 2 min the quick-CRP test is, therefore, feasible for immediate decision making as a part of clinical routine or clinical trials. Acknowledgements: The OptiRef project was supported by an unrestricted research grant from Novartis. The "QuickRead go" was provided free of charge by Orion Diagnostica Oy.

Disclosure of Interest: None declared

DOI: 10.1136/annrheumdis-2018-eular.4457

\section{FRI0195 \\ CLINICAL CHARACTERISTICS OF 897 CHINESE ANKYLOSING SPONDYLITIS/SPONDYLOARTHRITIS REAL WORLD COHORT: DATA FROM A CHINESE COHORT WITH SMART MANAGEMENT SYSTEM FOR SPONDYLOARTHRITIS (SMSP)}

X. Ji, J. Zhu, J. ZHANG, F. Huangon behalf of SMSP co-authors. Rheumatology, Chinese PLA General Hospital, Beijing, China

Background: With increasing global popularity of smartphone technology, there is a great opportunity for using mobile phone applications for disease management. Smart Management System for Spondyloarthritis (SpA) (SMSP) created a smart management system for SpA using eHealth technologies in China.

Objectives: The aim of this study was to report major characteristics of Chinese ankylosing spondylitis patients derived from a large, longitudinal and prospective database with SMSP.

Methods: SMSP was designated for multicenter, consecutive, and prospective cohorts, including patients' mobile terminal, the physician workstation system and communication system. Patients' portal was used for self-assessment prior visiting clinics, short message consultation, monitoring symptoms between clinic visits as well as uploading/downloading medical records, while physician' portal was used for professional assessment at clinic, scheduled visits reminder, sending self-management strategies at intervals and making recommendations and delivering patient-specific guidance to the individual. In this preliminary analysis, all patients fulfilled the modified New York criteria. All data were collected online using SMSP.

Results: From April 2016 to June 2017, data were extracted online from the physician workstation system in 4 rheumatology centres across China. There was a total of 2790 times self-assessment of BASDAI, BASFI performed by patients (median times=3.1, from 1 to 14 ) and a total of 1960 evaluation performed by the physician at the clinic (median times=2.1, from 1 to 10).

A total of 897 AS patients (mean age: $30.8 \pm 8.8$ years, male $82.7 \%$, HLA-B27 positive rate $88.0 \%$ ) were recruited in this baseline analysis. The median disease duration was 7.1 (0.01 to 39.63 ) years. A history or current symptoms suggestive of acute anterior uveitis, psoriasis, and inflammatory bowel disease were observed in $17.2 \%, 2.6 \%, 7.1 \%$ of the patients, respectively. Differences in symptom duration ( $\leq 5$ years, 5 years to 10 years and $>10$ years) were analysed. Acute anterior uveitis and inflammatory bowel disease were detected significantly more frequently in patients with symptom duration of $>10$ years $(27.0 \%, 11.0 \%$, respectively), shown in table 1 .

According to the ASDAS, at the baseline visit, $20.1 \%$ of patients achieved inactive disease, $30.8 \%$ with moderate disease activity, $37.3 \%$ with high disease activity and $10.6 \%$ with very high disease activity. The most commonly used medication was NSAIDs (98.9\%). The patients using biological DMARDs possessed a percentage of $15.5 \% .12 .8 \%$ of the patients used etanercept which was the most commonly used biological DMARDs. $64.7 \%$ of the patients used conventional synthetic DMARDs

Abstract FRI0195 - Table 1. Demographics and baseline clinical characteristics of the tota cohort

\begin{tabular}{|c|c|c|c|c|}
\hline Characteristic & $\begin{array}{l}\text { Durations5 years } \\
\qquad(n=292)\end{array}$ & $\begin{array}{l}5 \text { years<Durations } 10 \\
\text { years }(n=322)\end{array}$ & $\begin{array}{l}\text { Duration>10 years } \\
\qquad(n=283)\end{array}$ & Pvalue \\
\hline Age, mean $\approx$ SD months & $27.4 \pm 8.2$ & $29.0 \pm 7.2$ & $36.2 \pm 8.5$ & $<0.001$ \\
\hline $\begin{array}{l}\text { Age at disease onset, mean } \\
\pm S O \text { months }\end{array}$ & $24.8 \pm 8.3$ & $21.7 \pm 7.1$ & $20.9 \pm 7.2$ & $<0.001$ \\
\hline Duration, mean $\approx S O$ years & $2.7 \pm 1.4$ & $7.3 \div 1.4$ & $15.3 \pm 5.4$ & $<0.001$ \\
\hline Male sex (X) & $235(80.5 \%)$ & $274(85.1 \%)$ & $233(82.3 \%)$ & 0.313 \\
\hline HLA-827 positive (X) & $241(88.9 \%)$ & $254(89.1 \%)$ & $210(85.7 \%)$ & 0.411 \\
\hline Family history positive (\%) & $67(22.9 \%)$ & $84(26.3 \%)$ & $75(26.7 \%)$ & 0.523 \\
\hline $\begin{array}{l}\text { Peripheral arthritis } \\
\text { (current, } \%_{0} \text { ) }\end{array}$ & $32(11.5 \%)$ & $37(11.9 \%)$ & $29(10.7 \%)$ & 0.907 \\
\hline Enthesitis (current, $\mathbf{x )}$ & $52(18.7 \%)$ & So (16.1\%) & $35(13.0 \%)$ & 0.185 \\
\hline BASDAI, median (Q1-Q3) & $1.9(1.0-3.3)$ & $2.0(1.0-3.4)$ & $2.2(1.3 .3 .8)$ & 0.023 \\
\hline BASFl, median (Q1-Q3) & $0.8(0.1-2.1)$ & $1.1(0.2 \cdot 2.2)$ & $1.5(0.5-3.0)$ & $<0.001$ \\
\hline ESR, median (Q1-Q3) & $9.0(3.0-19.0)$ & $10.0(3.0-24.5)$ & $13.0(6.0-26.0)$ & 0.050 \\
\hline CRP, median (Q1-Q3) & $5.4(2.6-15.0)$ & $6.0(3.0-16.8)$ & $8.2(3.2-18.1)$ & 0.713 \\
\hline $\begin{array}{l}\text { ASOAS-CRP, median (Q1. } \\
\text { Q3) }\end{array}$ & $1.8(1.3 \cdot 2.7)$ & $2.0(1.5 \cdot 2.8)$ & $2.2(1.5 \cdot 2.9)$ & 0.095 \\
\hline BASMI, median (Q1-Q3) & $0.0(0.0-1.0)$ & $0.0(0.0-2.0)$ & $2.0(0.0-4.0)$ & $<0.001$ \\
\hline Acute anterior uveitis (X) & $32(11.0 \%)$ & $46(14.4 \%)$ & $76(27.0 \%)$ & $<0.001$ \\
\hline $\begin{array}{l}\text { Inflammatory bowel } \\
\text { disease (\%) }\end{array}$ & $11(3.8 \%)$ & $22(6.9 \%)$ & $31(11.0 \%)$ & 0.003 \\
\hline Psoriasis (\%) & $5(1.7 \%)$ & $9(2.8 \%)$ & $10(3.6 \%)$ & 0.387 \\
\hline NSAIDS (current, \%) & $216(98.6 \%)$ & $250(99.6 \%)$ & $222(98.2 \%)$ & 0.349 \\
\hline DMARD (current, $\%$ ) & $135(61.6 \%)$ & $168(66.9 x)$ & $147(65.0 \%)$ & 0.483 \\
\hline $\begin{array}{l}\text { TNF-a inhibitors } \\
\text { (current, } \% \text { ) }\end{array}$ & $35(16.0 \%)$ & $40(15.9 \%)$ & $33(14.6 \%)$ & 0.898 \\
\hline
\end{tabular}




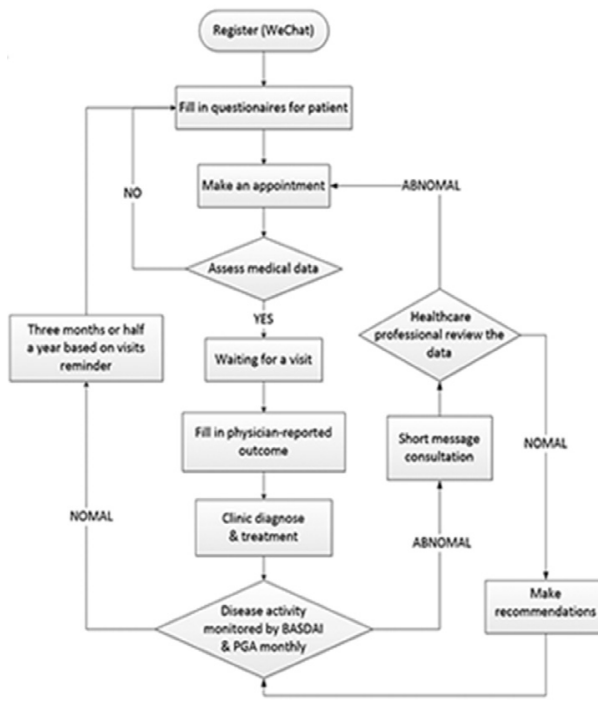

Conclusions: SMSP is an effective mobile interface to serve AS patients performing self-management as well as to supply physicians with valuable and reliable data with a minimal bias for online data collection and automatic quality controls. This large cohort may improve our knowledge of the characteristics, pathogenesis and natural course in Chinese patients with AS.

Disclosure of Interest: None declared

DOI: 10.1136/annrheumdis-2018-eular.1630

\section{FRI0196 TRADITIONAL DXA UNDERESTIMATES BONE MINERAL DENSITY OF THE SPINE IN AXIAL SPONDYLOARTHROPATHY}

G. Fitzgerald, T. Anachebe, F. O' Shea. Department of Rheumatology, St James's Hospital, Dublin 8, Ireland

Background: Axial spondyloarthropathy (axSpA) is an inflammatory arthritis which can lead to new bone formation (syndesmophytes) and ankylosis of the spine. Osteoporosis is a recognised feature of axSpA, but can be challenging to diagnose. Traditional dual-energy $x$-ray absorptiometry (DXA) in the antero-posterior (AP) projection of the spine can overestimate bone mineral density (BMD) due to the presence of syndesmophytes, potentially under-diagnosing osteoporosis. There is a real need to find an accurate method to assess BMD in axSpA patients. Lateral DXA of the lumbar spine is unaffected by syndesmophyte formation and may be a promising tool.

Objectives: The aim of this study is to:

1. investigate different projections of DXA of the lumbar spine in axSpA patients 2. assess the effect of syndesmophytes on spine BMD.

Methods: AxSpA patients were assessed with clinical exam, questionnaires and laboratory investigations. The burden of syndesmophytes on lateral $\mathrm{x}$-rays of the lumbar and cervical spine was assessed with the validated modified Stoke Ankylosing Spondylitis Spinal Score (mSASSS) score, which ranges from 0-72 (higher scores indicate more severe disease). DXA was performed of the spine in both the AP and lateral projections. SPSS was used for statistical analysis.

Results: One hundred patients with axSpA were recruited: $78 \%(n=78)$ male, mean (SD) age $52^{12}$ years, disease duration $26^{13}$ years, $85 \%(n=85)$ fulfil modified New York criteria. The median (IQR) mSASSS score was $10^{3 .}$

Lumbar spine BMD was lower when measured by lateral DXA rather than AP $\left(0.76 \vee 1.11 \mathrm{~g} / \mathrm{cm}^{2}, p<0.01\right)$. Lateral DXA detected more cases of spinal osteopenia or osteoporosis than AP $(21 \% \vee 44 \%, p<0.01)$. Lateral spine BMD reduced with longer duration of disease $(r=-0.3, p=0.02)$, whereas AP spine BMD increased with age $(r=0.3, p=0.01)$. Women had significantly more cases of osteoporosis at the lumbar spine than men when measured by lateral DXA $(32 \% \mathrm{v}$ $12 \%, p=0.02$ ), but not by AP DXA.

A higher mSASSS, reflecting more syndesmophytes/new bone formation, was associated with a rising AP spine $B M D(r=0.5, p<0.01)$, but had no effect on lateral spine BMD. The gap between AP and lateral spine BMD, i.e. when AP BMD was higher than lateral BMD, increased significantly $(p<0.05)$ with increasing age $(r=0.38)$, disease duration $(r=0.37)$ and mSASSS $(r=0.52)$. mSASSS was the strongest independent predictor of a difference between AP and lateral BMD measurements, suggesting that syndesmophyte formation interferes with AP DXA assessment of the spine.

Conclusions: AP DXA of the spine is affected by a higher burden of syndesmophytes (new bone formation), raising concerns that traditional DXA assessment may miss cases of osteoporosis. We suggest that lateral DXA of the spine may be a more accurate tool to detect osteoporosis in axSpA patients.

Disclosure of Interest: None declared

DOI: 10.1136/annrheumdis-2018-eular.6296

\section{FRI0197 ASSOCIATION OF THE ELECTROCARDIOGRAPHIC DISTURBANCES WITH AORTIC ROOT DILATION IN PATIENTS WITH ANKYLOSING SPONDYLITIS}

H.S. Park ${ }^{1}$, A. Laiz ${ }^{1}$, C. Alonso ${ }^{2}$, S. Jeria Navarro ${ }^{1}$, A. García-Guillén ${ }^{1}$, M. Millan ${ }^{1}$, P. Moya ${ }^{1}$, B. Magallares ${ }^{1}$, I. Castellvi ${ }^{1}$, C. Diaz-Torne ${ }^{1}$, S. Fernandez ${ }^{1}$, J. Casademont ${ }^{3}, \mathrm{H}$. Corominas ${ }^{1} .{ }^{1}$ Rheumatology; ${ }^{2}$ Cardiology, ${ }^{3}$ Internal Medicine, H.U. Sant Pau, Barcelona, Spain

Background: Ankylosing spondylitis (AS) is a disease with very characteristic extraarticular organ involvements. Cardiac conduction disturbances and aortic root diseases are some of the most particular manifestations of this disease ${ }^{1}$. The most frequent conduction disturbances are atrioventricular blocks (AVB), bundle branch blocks (BBB) and intraventricular conduction disturbances (IVCD)2. The prevalence of AVB is $3 \%$ and $8 \%$ for IVCD in the general population ${ }^{3}$. In some cross-sectional studies of the AS population ${ }^{4,5}$ the prevalence was reported to be around $4.6 \%-9 \%$ for AVB and $4 \%-29 \%$ for IVCD. Some studies propose that there may be a relation between the conduction disturbances and the inflammation of the aortic root due to disease activity $6,7,8$.

Objectives: This study aims to evaluate association between the electrocardiographic alterations (AVB, BBB, IVCD) and aortic root dilation in patients with AS. Methods: Out of a registry of 118 patients from a spondyloarthritis consultation, we selected patients with AS according to New York criteria. We included those patients who had underwent an electrocardiography (EKG) and an echocardiography, in ordeer to rule out heart disease or to check up because of long term AS. Demographical and clinical data (cardiovascular risk factors, past heart disease, presence of arthritis, enthesitis, dactylitis, uveitis and HLAB27) were collected. The EKG were reevaluated looking for IVCD, AVB or BBB by a blinded arrhythmologist. Echocardiographical data about aortic root dilation were collected using aortic root diameter adjusted by body surface area. We carried out chi squared analysis as well as a comparison of proportions. We summarised descriptive data of our sample in table 1 .

Results: Out of 118 patients, 38 patients met inclusion criteria. Fourteen of them $(36.8 \%)$ were women. The average age was 60.3 years old and mean disease duration was 19.62 years.

Conduction disturbances was present in $12(31.5 \%)$ patients of whom 4 were AVB (10.5\%), 5 BBB $(13.2 \%)$ and 3 IVCD $(7.8 \%)$. Aortic root dilation was found in 6 $(15.8 \%)$ of the 38 patients.

The conduction disturbances showed a statistically significant association with aortic root dilation (chi square $\mathrm{p}=0.02$ ). In comparison of two proportions, the prevalence of aortic root dilation in abnormal EKG group (0.67 IC95\% $0.36 \%-$ $0.97 \%$ ) was significantly higher than normal EKG group (0.6 IC95\% $0.36-$ $0.97) \mathrm{p}=0.02$.

Abstract FRI0197 - Table 1

\begin{tabular}{|l|c|}
\hline Variable & Number (patients)/Proportion (\%) \\
\hline Women & $14 / 36.84 \%$ \\
\hline B27 & $29 / 80.56 \%$ \\
\hline Arthritis & $14 / 36.84 \%$ \\
\hline Enthesitis & $13 / 34.21 \%$ \\
\hline Uveitis & $5 / 13.16 \%$ \\
\hline Aortic root dilation & $12 / 31.5 \%$ \\
\hline Aortic insufficiency & $12 / 31.5 \%$ \\
\hline Exsmoker & $23.68 \%$ \\
Smoker & $34.21 \%$ \\
\hline Hypertension & $21 / 56.76 \%$ \\
Dyslipemia & $22 / 59.49 \%$ \\
Diabetes & $10 / 27.02 \%$ \\
\hline Valve disease & $2 / 5.55 \%$ \\
\hline Ischaemic disease & $7 / 29.44 \%$ \\
\hline AVB & $4 / 10.52 \%$ \\
\hline Left BB & $1 / 2.63 \%$ \\
\hline Right BB & $3 / 7.89$ \\
\hline Anterior BB & $1 / 2.63 \%$ \\
\hline Intraventricular conduction & $3 / 7.89 \%$ \\
\hline disturbances & \\
\hline
\end{tabular}

Conclusions: The prevalence of aortic root dilation and conduction disturbances was higher in our sample than in the general population. In our 